\title{
Influence of Jatropha Fruit Maturity on Seed Oil Yield, Composition and Heat of Combustion of Derived Biodiesel
}

\author{
Mbako Jonas, Clever Ketlogetswe, Jerekias Gandure \\ Department of Mechanical Engineering, University of Botswana, Gaborone, Botswana \\ Email: jonasmbako@yahoo.com
}

How to cite this paper: Jonas, M., Ketlogetswe, C. and Gandure, J. (2018) Influence of Jatropha Fruit Maturity on Seed Oil Yield, Composition and Heat of Combustion of Derived Biodiesel. Energy and Power Engineering, 10, 77-86.

https://doi.org/10.4236/epe.2018.103006

Received: February 5, 2018

Accepted: March 19, 2018

Published: March 22, 2018

Copyright (c) 2018 by authors and Scientific Research Publishing Inc. This work is licensed under the Creative Commons Attribution International License (CC BY 4.0).

http://creativecommons.org/licenses/by/4.0/

\begin{abstract}
Maturity of Jatropha fruits has influence on oil yield, chemical composition and physicochemical properties of derived biodiesel. Oil yield was determined using soxhlet extraction while biodiesel was prepared through the process of transesterification. Fatty acid profile was determined according to test method EN 14103 using Agilent Technologies GC System 7890. The calorific value of biodiesel was determined using Oxygen Bomb Calorimeter, IKA C200 according to test method ASTM D5865. Results showed that Yellow Jatropha fruit seeds have the highest oil yield and energy content, coupled with the best mix of fatty acid methyl esters.
\end{abstract}

\section{Keywords}

Fruit Maturity, Biodiesel, Oil Yield, Energy Content, Fatty Acid Profile

\section{Introduction}

Jatropha plant has received much attention as a potential feedstock for biodiesel production. The plant bares seeds are rich in oil, which can be converted into biodiesel. It has a good adaptation to a large variety of soil and climatic conditions including dry and semiarid conditions which are unsuitable for food production [1] [2]. During the maturation process of fruits, seeds undergo physical and chemical changes that determine the quality of the oil [3]. Maturity of fruits is usually determined with colour change once they have reached their maximum growth size. During maturation, Jatropha fruits change colour from green to green yellow, yellow, yellow brown and finally brown dry. Feedstock of low quality in terms of physical and chemical properties requires pretreatment prior to conversion to biodiesel which increases costs of production. For example, 
feedstock with high levels of free fatty acids (FFA) requires pretreatment to reduce the levels of FFA which are undesirable during conversion of seed oil to biodiesel. Pretreatment of feedstock comes at a cost which then increases the overall cost of biodiesel production.

Therefore, knowledge of effect of maturity of Jatropha fruits is very important to the biodiesel production industry which considers Jatropha as a feedstock. It helps in determining the right time of harvest for sustaining better quality oil from the seeds and highest possible oil yield while minimising production costs. High oil yield and quality from the seeds will ensure production of more biodiesel of high quality.

Fatty acid composition has a significant influence in physicochemical properties of seed oil and biodiesel [4] [5] [6]. Fatty acid composition influences properties that include cetane number, energy content, viscosity, density, iodine value, oxidative stability, cloud and pour point. Previous findings [7] have shown that energy content (heating value) decreases with increase in degree of unsaturation (double bonds) due to deficiency in hydrogen atoms.

Increase in oleic and linoleic acids has been shown to decrease energy content and other properties such as cetane number. Linoleic acid tends to decrease these parameters even more since it is polyunsaturated. On the other hand, an increase in palmitic acid and stearic acid in seed oil or biodiesel increase energy content and cetane number since they are saturated. Increasing degree of saturation and trans-configuration in fatty acids increases overall viscosity of seed oil and biodiesel, while increase in unsaturation decreases viscosity [5]. Therefore, increase in linoleic acid and oleic acid reduces overall viscosity. It is recommended to have an increased amount of short chain and saturated methyl ester contents in fuel to reduce carbon monoxide $(\mathrm{CO})$ and nitrogen oxides $\left(\mathrm{NO}_{\mathrm{x}}\right)$ emission [6]. In the case of Jatropha oil, palmitic acid has a relatively shorter chain and is saturated, therefore an increase in palmitic acid content will significantly reduce both $\mathrm{CO}$ and $\mathrm{NO}_{\mathrm{x}}$ emissions. Stearic acid has a relatively longer chain and is saturated. Its presence therefore contributes to reduction of $\mathrm{CO}$ and $\mathrm{NO}_{\mathrm{x}}$ emissions.

This paper therefore investigates influence of fruit maturity on selected physicochemical properties of seed oil and its derived biodiesel. The properties covered in this paper are seed oil yield, free fatty acids, fatty acids composition and calorific value.

\section{Materials and Methods}

Jatropha fruits were harvested from Mmadinare village in Botswana $\left(21.8811^{\circ} \mathrm{S}\right.$, $27.7514^{\circ} \mathrm{E}$ ) at four different maturity stages namely, green yellow, yellow, yellow brown and brown dry. In the present study, Mmadinare village was selected as a study area because Jatropha plant is believed to be doing very well in the area. A map (satellite image) of this location is shown in Figure 1. Jatropha trees are found in homesteads (as demonstrated by Figure 1), and are planted along the 


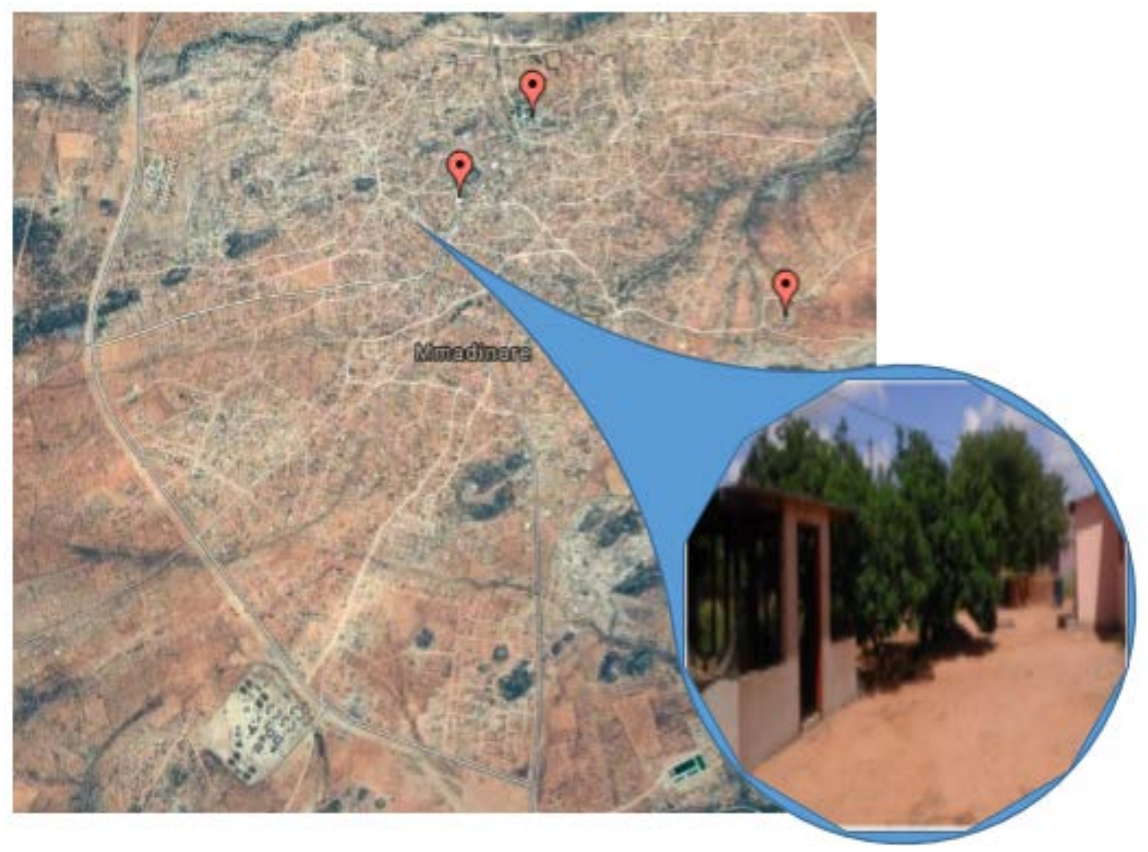

Figure 1. A map (satellite image) of Mmadinare village.

fence as wind breakers and for providing shade. These fruit maturity stages are shown in Figure 2. The seeds were removed from the fruits within 24 hours of harvesting and dried naturally (air dying) for two weeks. Dried Jatropha seeds were de-shelled to obtain the kernels. The seed kernels were then ground into powder using a mechanical grinder in preparation for solvent extraction.

\subsection{Oil Extraction and Yield}

Seed kernel powder was weighed $(40 \mathrm{~g})$ and placed in a soxhlet extractor with a cotton wool at the base. The soxhlet extractor was attached to a $500 \mathrm{ml}$ round bottom flask and condenser attached at the top of the soxhlet extractor. A mixture of $\mathrm{n}$-hexane $(300 \mathrm{ml})$ and isopropanol $(100 \mathrm{ml})$ were added to the flask. A heating mantle was used to boil the mixture during the extraction process. The extraction was carried out continuously for 6 hours. The extraction mixture was dried by adding 4 spatulas of anhydrous sodium carbonate. The dried extraction mixture was filtered into pre-weighed $500 \mathrm{ml}$ round bottom flask using a paper filter (Grade 1: $11 \mu \mathrm{m}$ ) to remove insoluble solid material. Crude seed oil was recovered from the mixture by evaporating the $\mathrm{n}$-hexane and propanol using a rotary evaporator (BUIKICHI Rotavapor R-114). Traces of remaining solvent were removed by blowing the oil with Nitrogen gas. Weight of the oil was weighed and recorded. The procedure was repeated for all the four maturity stages.

The percentage oil content in Jatropha seeds was determined by measuring the weight of the seeds before extraction of the oil then weighing the seed oil after extraction. This procedure was repeated three times for each sample then calculated the average. Oil yield was then calculated using Equation (1) below. 


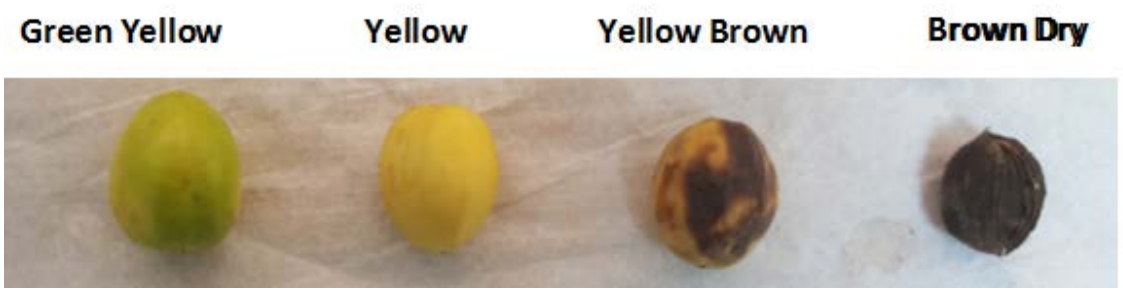

Figure 2. Jatropha fruits at four different maturity stages.

$$
\% \text { Oil yield }=\frac{\text { total weight of seed oil extracted }}{\text { total weight of seeds before extraction }} \times 100 \%
$$

\subsection{Free Fatty Acids}

Potassium Hydroxide $(\mathrm{KOH})$ solution with normality of 0.1 was prepared by dissolving $5.61 \mathrm{~g}$ of white deliquescent $\mathrm{KOH}$ pellets in $10 \mathrm{ml}$ of deionized water then adding $1 \mathrm{~L}$ of $99 \%$ ethanol. The solution was left in a tightly stoppered bottle for 24 hours to ensure complete dissolution. The solution (KOH) was standardized by pipetting $50 \mathrm{ml}$ of $0.1 \mathrm{M}$ hydrochloric acid (HCL) into a conical flask then adding 5 drops of phenolphthalein indicator. The HCL was then titrated with Potassium Hydroxide solution until permanent pink colour appeared ( $1 \mathrm{ml}$ of $0.5 \mathrm{M} \mathrm{HCL}$ acid is equivalent to $0.02806 \mathrm{~g}$ of $\mathrm{KOH}$ ). Oil sample of about $2 \mathrm{~g}$ was measured and put into a conical flask. $50 \mathrm{ml}$ of a mixture of $95 \%$ ethanol/ toluene, $1 / 1, \mathrm{v} / \mathrm{v}$ and 5 drops of phenolphthalein indicator were added to the flask. The mixture was then titrated with $\mathrm{KOH}$ while stirring vigorously until a permanent pink colour appeared. Free fatty acids were then calculated using Equation (2) below. The procedure was repeated five times for each sample then calculated the average.

$$
\% F F A=\left(\frac{V \times N \times M W_{\mathrm{C} 18: 1}}{W \times 1000}\right)
$$

where:

$V=$ potassium hydroxide solution consumed in the titration $(\mathrm{mL})$

$N=$ normality of the potassium hydroxide solution

$W=$ weight of oil sample $(\mathrm{g})$

$M W=$ molecular weight $(\mathrm{g} / \mathrm{mol})$

$M W_{\text {кон }}=56.1 \mathrm{~g} / \mathrm{mol}$

$M W_{\mathrm{C} 18: 1}=282.5 \mathrm{~g} / \mathrm{mol}$ (expressed as oleic acid)

\subsection{Methyl Ester Preparation}

Fatty acids in the seed oil were converted to methyl esters (biodiesel) since gas chromatography (GC) analyzes fatty acids either as free fatty acids or as fatty acid methyl esters (FAME). $1 \mathrm{~L}$ of seed oil was added to a three neck round bottom flask (reactor). $6 \mathrm{~g}$ of potassium hydroxide (catalyst) was dissolved in 800 $\mathrm{mL}$ of methanol then the solution was added to the reactor. The reactor was then placed on a heating mantle and the mixture was heated at $60^{\circ} \mathrm{C}$ throughout the 
reaction process. A condenser was fitted to the reactor to reduce loss of methanol. The mixture was stirred vigorously throughout the reaction process which lasted for 1 hour. The reaction products were then poured into a separating funnel and left for at least 24 hours to allow glycerol and methyl esters to separate under gravity. After separation, excess methanol was recovered from the methyl esters using a rotary evaporator (BUIKICHI Rotavapor R-114).

\subsection{Fatty Acid Composition}

The composition and quantity of fatty acid methyl ester (FAME) was determined according to test method EN 14,103, using Agilent Technologies GC System 7890. A gas chromatograph (GC) equipped with a HP-5MS capillary column $(30 \mathrm{~m} \times 250 \mu \mathrm{m} \times 0.25 \mu \mathrm{m})$ and an automated injector. The GC was connected to Agilent Technologies 5975C mass spectrometer with Triple-Axis detector. Helium was used as carrier gas at a pressure of $72 \mathrm{kPa}$ and flow rate of 64 $\mathrm{mL} / \mathrm{min} .1 \mu \mathrm{L}$ of sample was injected using an automated injector. The initial oven temperature was set to $100^{\circ} \mathrm{C}$ for 4 minutes, which was then increased at a rate of $7^{\circ} \mathrm{C} / \mathrm{min}$ to $235^{\circ} \mathrm{C}$, then $10^{\circ} \mathrm{C} / \mathrm{min}$ to $300^{\circ} \mathrm{C}$ for 7 minutes. The injector and detector temperatures were set to $325^{\circ} \mathrm{C}$. Total run time was 36 minutes.

\subsection{Calorific Value}

The calorific value of biodiesel was determined using Oxygen Bomb Calorimeter, IKA C200, in accordance to test method ASTM D5865. About 1g of sample was measured into crucible. A piece of thread was attached to the fuse wire with the other end of the thread immersed in the sample. The bomb head (with sample) was then inserted into the bomb cylinder then the screw cap was screwed firmly to a solid stop. The bomb was filled with oxygen to a pressure of 30 bar. When the bomb was ready it was put into the calorimeter. The bomb was handled carefully to ensure that the sample was not disturbed. Distilled water was filled to the mark into the calorimeter. The calorimeter was then started and run for about 26 minutes. Measured data was displayed through the computer.

\section{Results and Discussions}

\subsection{Seed Oil Content}

Seed oil content is the amount of lipid/oil contained in seeds expressed in terms of percentage. The level of oil contained in Jatropha seeds have been found to vary as the fruit matures. During the various fruit maturity stages, seed oil content varies as it appears in Figure 3. During the early maturity of the fruit, oil yield in seeds is minimal. Results show that seeds derived from green yellow fruits contain least amount of oil, $41.7 \%$. As the fruit matures to yellow, oil content in seeds increases to $45.8 \%$ which is similar to when the fruit is brown dry which is the final stage of Jatropha fruit maturity. When the fruit is yellow brown, there is a decline in seed oil content. According to the results, seeds from yellow brown fruits contain $44.5 \%$ oil. Therefore, seeds extracted from yellow 


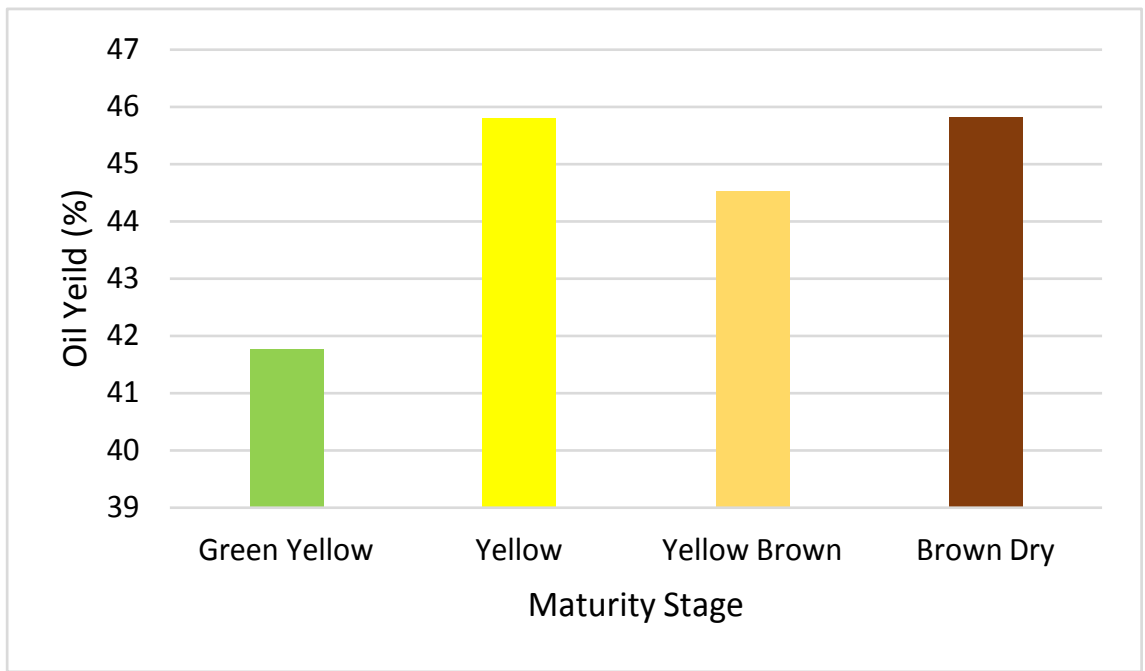

Figure 3. Variation of Seed oil yield with fruit maturity.

and brown dry fruits contains relatively maximum oil content.

\subsection{Free Fatty Acids}

The amount of free fatty acids (FFA) of Jatropha seed oil at different fruit maturity stages was analyzed as described in section 2.2. Results obtained are presented in Figure 4. Green yellow fruits yield oil with relatively high level of free fatty acids, above the limit set by international standards $(>1 \% \mathrm{w} / \mathrm{w})$. For the other three stages (yellow, yellow brown and brown dry), the level of FFA is below $1 \%$. However, oil derived from yellow brown fruits contain relatively higher FFA content ( $0.93 \%)$ than yellow and brown dry stages. Of all the maturity stages, oil derived from yellow fruits contains least FFA content $(0.87 \%)$. Higher levels of free fatty acids reduce methyl ester yield during transesterification process [8]. Therefore, oil derived from yellow fruits will be preferred over the other maturity stages since it contains least FFA content.

\subsection{Fatty Acid Composition}

The main fatty acids in Jatropha seed oil were found out to be Linoleic acid, Oleic acid, Palmitic acid and Stearic acid. These fatty acids are sown in Table 1. This findings are supported by previous researchers [9] [10] [11] [12] [13] who characterized Jatropha seed oil from brown dry fruits in various geographical origins. Linoleic acid is a polyunsaturated fatty acid. Oleic acid is a mono unsaturated fatty acid. Palmitic acid and Stearic acid are both saturated fatty acids. These fatty acids make a significant portion of the seed oil across all the maturity stages of the fruit. Variation of these fatty acids in seed oil with fruit maturity is shown in Figure 5. For all maturity stages, unsaturated fatty acids make up more than $70 \%$ of total fatty acids in Jatropha seed oil. Therefore Jatropha seed oil is more unsaturated. Almost half of Jatropha seed oil is made up of Linoleic acid which has two double bonds in its molecular structure. 


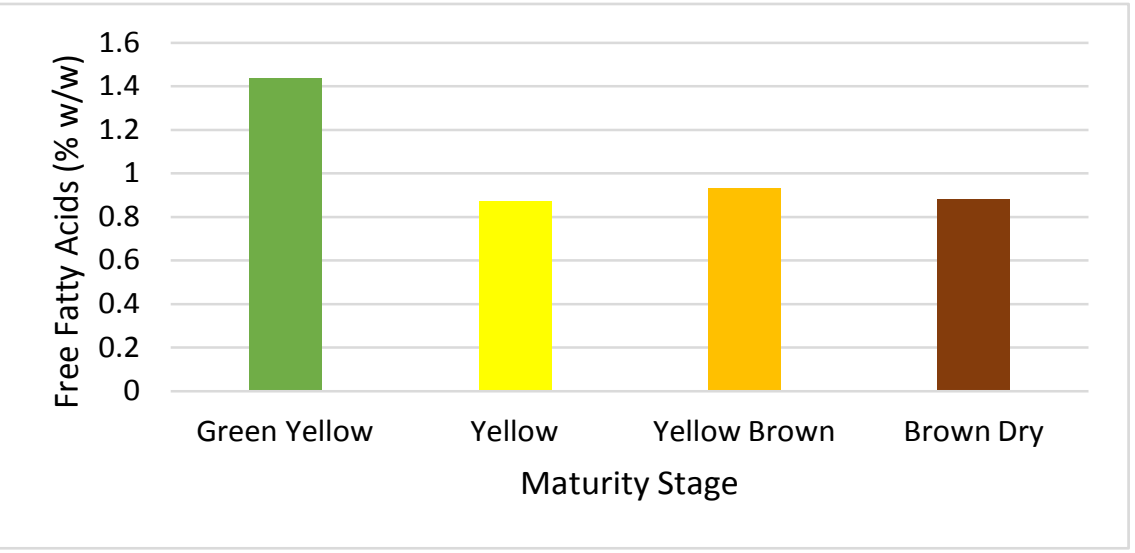

Figure 4. Variation of free fatty acids in Seed oil with fruit maturity.

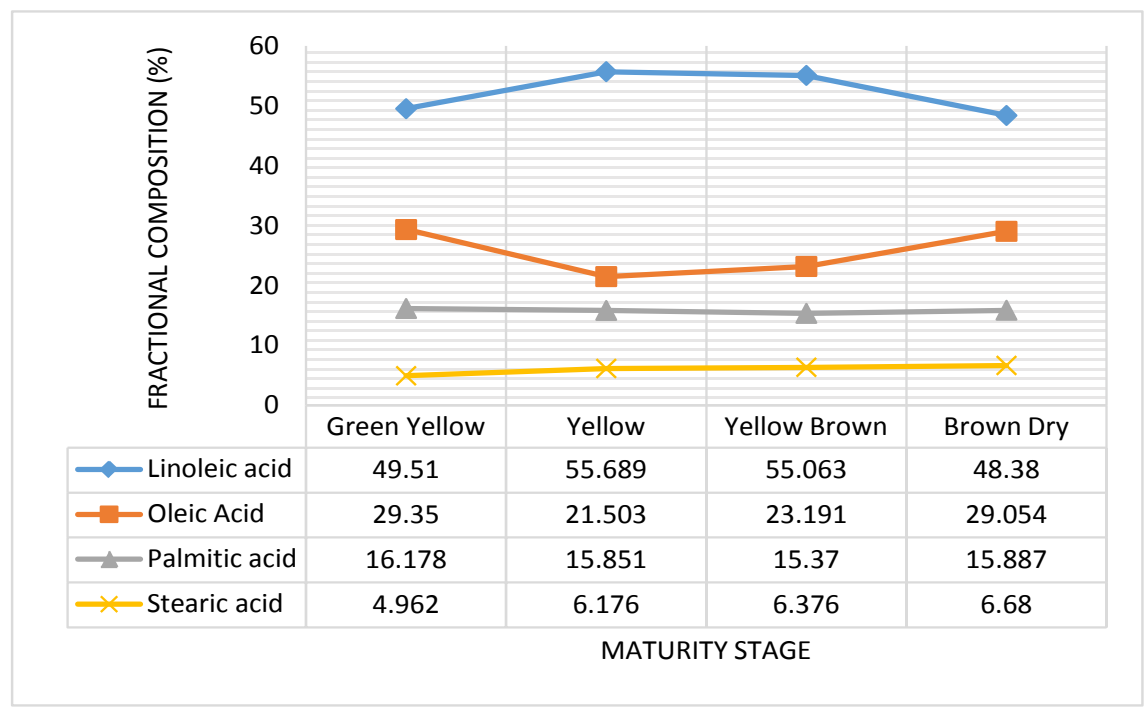

Figure 5. Fatty acid profile of Jatropha seed oil at different fruit maturity stages.

Fractional composition of Palmitic acid and Stearic acid remains almost constant across all the maturity stages of Jatropha fruits. Linoleic acid which is the most abundant, increases slightly when the fruit turns yellow then decreases slightly during the final maturity stage of the fruit. Oleic acid on the other hand decreases slightly when the fruit turns yellow then increases slightly when the fruit turns brown dry.

\subsection{Calorific Value}

The Calorific value of a fuel is the amount of heat released by a unit weight or unit volume of a substance during complete combustion [14]. It indicates the amount of energy available in a fuel. Fuels with higher calorific value contain more energy [15] [16]. According to the results in Figure 6, biodiesel produced from seed oil derived from yellow Jatropha fruits contains relatively highest energy of $38.54 \mathrm{KJ} / \mathrm{g}$ and yellow brown contains least energy content of 38.24 $\mathrm{KJ} / \mathrm{g}$. However, it is important to note that variation in energy content in 


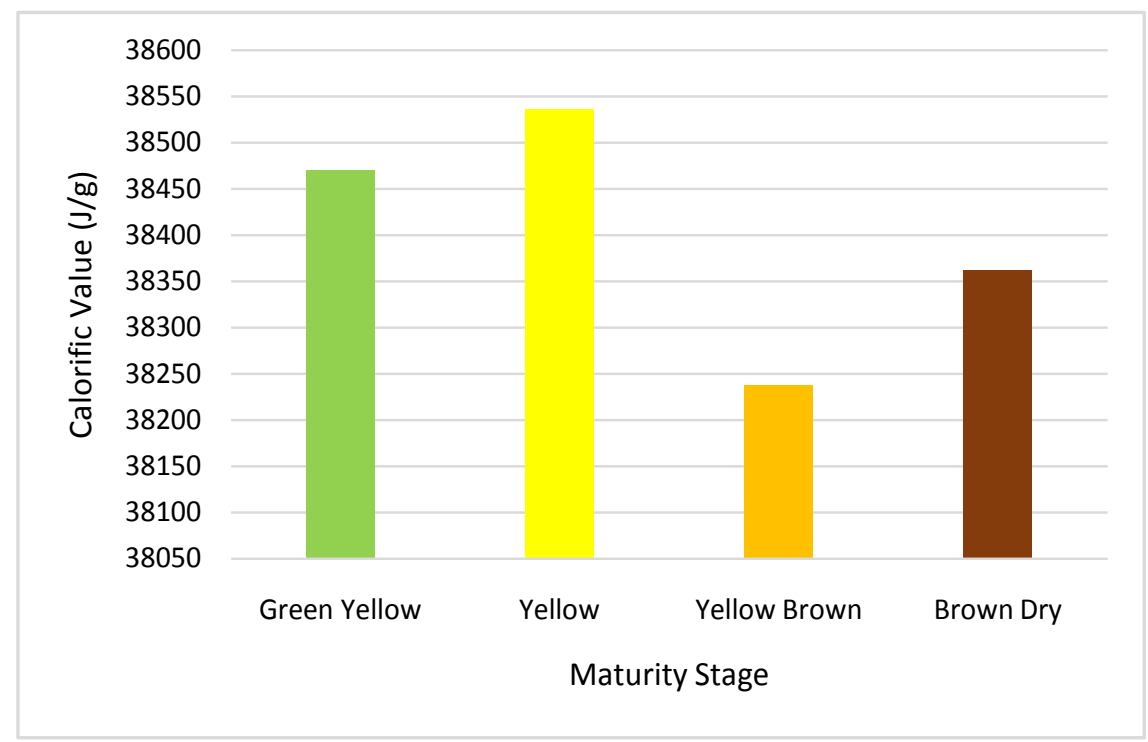

Figure 6. Calorific values of biodiesel produced from Jatropha seed oils of different maturity levels.

Table 1. Chemical description of fatty acids found in Jatropha seed oil in the form of fatty acid methyl esters (FAME).

\begin{tabular}{|c|c|c|c|}
\hline Fatty Acid & Formula & Structure & Molecular Structure \\
\hline $\begin{array}{c}\text { Linoleic acid } \\
(14,17-\text { Octadecadienoic acid })\end{array}$ & $\mathrm{C}_{19} \mathrm{H}_{34} \mathrm{O}_{2}$ & C19:2 & \\
\hline $\begin{array}{c}\text { Oleic acid } \\
\text { (9-Octadecenoic acid) }\end{array}$ & $\mathrm{C}_{19} \mathrm{H}_{36} \mathrm{O}_{2}$ & C19:1 & \\
\hline $\begin{array}{c}\text { Palmitic acid } \\
\text { (Hexadecanoic acid) }\end{array}$ & $\mathrm{C}_{17} \mathrm{H}_{34} \mathrm{O}_{2}$ & C17:0 & \\
\hline $\begin{array}{c}\text { Stearic acid } \\
\text { (Octadecanoic acid) }\end{array}$ & $\mathrm{C}_{19} \mathrm{H}_{38} \mathrm{O}_{2}$ & C19:0 & \\
\hline
\end{tabular}

biodiesel with maturity stage isn't significant since it's only $0.77 \%$. Biodiesel from green yellow fruits also contains higher energy than brown dry and yellow brown stages. Therefore biodiesel from yellow fruits will be preferred since fuels with higher calorific value produce more power in the engine whereas fuels with less calorific value tend to burn inefficiently thus causing lot of exhaust and air-pollution [14].

\section{Conclusions}

1) Yellow Jatropha fruits had the highest yield of seed oil, least FFA level and yield biodiesel with relatively highest energy content.

2) The main fatty acids in Jatropha seed oil are Linoleic acid, Oleic acid, Palmitic acid and Stearic acid and their fractional composition varies with fruit maturity stage.

3) Variation in energy content in biodiesel with maturity stage isn't significant since it's only $0.77 \%$ between highest and lowest. 


\section{References}

[1] Openshaw, K. (2000) A Review of Jatropha curcas. An Oil Plant of Unfulfilled. Biomass and Bioenergy, 19, 1-15. https://doi.org/10.1016/S0961-9534(00)00019-2

[2] Barua, P.K. (2011) Biodiesel from Seeds of Jatropha Found in Assam, India. International Journal of Energy, Information and Communications, 2, 53-65.

[3] Dranski, J.A.L., Pinto Jr., A.S., Steiner, F., Zoz, T., Malavasi, U.C., de Matos Malavasi, M. and Guimaraes, V.F. (2010) Physiological Maturity of Seeds and Colorimetry of Fruits of Jatropha curcas L. Revista Brasileira de Sementes, 32, 158-165. https://doi.org/10.1590/S0101-31222010000400018

[4] Hoekman, S.K., Broch, A., Robbins, C., Ceniceros, E. and Natarajan, M. (2012) Review of Biodiesel Composition, Properties, and Specifications. Renewable and Sustainable Energy Reviews, 16, 143-169. https://doi.org/10.1016/j.rser.2011.07.143

[5] Caldeira, C., Freire, F., Olivetti, E.A. and Kirchain, R. (2017) Fatty Acid Based Prediction Models for Biodiesel Properties Incorporating Compositional Uncertainty. Fuel, 196, 13-20. https://doi.org/10.1016/j.fuel.2017.01.074

[6] Ruhul, M.A., Abedin, M.J., Rahman, S.M.A., Masjuki, B.H.H., Karem, A.A., Kalam, M.A. and Shancita, I. (2016) Impact of Fatty Acid Composition and Physicochemical Properties of Jatropha and Alexandrian laurel Biodiesel Blends: An Analysis of Performance and Emission Characteristics. Journal of Cleaner Production, 133, 1181-1189. https://doi.org/10.1016/j.jclepro.2016.06.017

[7] Gopinath, A., Sairam, K. and Velraj, R. (2013) Effect of Double Bond Equivalent of Biodiesels on their Heating Value and Cetane Number. Asian Journal of Chemistry, 25, 8732-8736. https://doi.org/10.14233/ajchem.2013.15385

[8] Berchmans, H.J. and Hirata, S. (2008) Biodiesel Production from Crude Jatropha curcas L. Seed Oil with a High Content of Free Fatty Acids. Bioresource Technology, 99, 1716-1721. https://doi.org/10.1016/j.biortech.2007.03.051

[9] Adebowale, K.O. and Adedire, C.O. (2006) Chemical Composition and Insecticidal Properties of the Underutilized Jatropha curcas Seed Oil. African Journal of Biotechnology, 5, 901-906.

[10] Abdullah, B.M., Yusop, R.M., Salimon, J., Yousif, E. and Salih, N. (2013) Physical and Chemical Properties Analysis of Jatropha curcas Seed Oil for Industrial Applications. International Journal of Chemical, Molecular, Nuclear, Materials and Metallurgical Engineering, 7, 893-896.

[11] Joshi, A., Singhal, P.K. and Bachheti, R.K. (2013) Variation in Oil Content and Physico-Chemical Properties of Jatropha curcus Seed Collected from Different Areas of Garwhal, Uttarakhand India. International Journal of ChemTech Research, 5, 2993-2999.

[12] Akbar, E., Yaakob, Z., Kamarudin, S.K., Ismail, M. and Salimon, J. (2009) Characteristic and Composition of Jatropha curcas Oil Seed from Malaysia and its Potential as Biodiesel Feedstock. European Journal of Scientific Research, 29, 396-403.

[13] Gopinath, A., Puhan, S. and Nagarajan, G. (2010) Effect of Biodiesel Structural Configuration on Its Ignition Quality. International Journal of Energy and Environment (IJEE), 1, 295-306.

[14] Kumari, R., Nirmala, N. and Caroline Joshi, S.S.D. (2014) Calorific Value Measurements and Optimization of Waste Cooking Oil Bio-Diesel, Crude Plastic Oil and Their Blends for the Synthesis of Low Cost High Energy Fuels. National Journal on Chembiosis, 5, 17-21. 
[15] Oliveira, L.E. and Da Silva, M.L.C.P. (2013) Comparative Study of Calorific Value of Rapeseed, Soybean, Jatropha curcas and Crambe Biodiesel. Renewable Energy and Power Quality Journal, 1, 679-682. https://doi.org/10.24084/repqj11.411

[16] Demirbas, A. (2005) Biodiesel Production from Vegetable Oils via Catalytic and Non-Catalytic Supercritical Methanol Transesterification Methods. Progress in Energy and Combustion Science, 31, 466-487.

https://doi.org/10.1016/j.pecs.2005.09.001 